\title{
How green are residential areas? An analysis of community greening emerging multi-source geo-data \\ Yiyong Chen ${ }^{1}$ \\ 1 Shenzhen Key Laboratory of Built Environment Optimization, School of Architecture \& Urban Planning, Shenzhen University, Shenzhen 518060, China \\ *Correspondence: chenyiy@szu.edu.cn
}

Abstract: Urban residential greening provides opportunities for social integration and physical exercise. These activities are beneficial to promoting citizens' mental health, relieving stress and reducing obesity and violent crimes. However, how to measure the distribution and spatial difference of green resources in urban residential areas have been controversial. This study takes the greening of urban residential units in Shenzhen City as its research object, measures the various greening index values of each residential unit, and analyses the spatial distribution characteristics of residential greening, regional differences and influencing factors. Large sample of street view pictures, urban land use and high-resolution remote sensing image data are employed to establish an urban residential greening database containing 14,196 residential units. This study proposes three greening indicators, namely, green coverage index, green view index, and accessible public green land index, for measuring the green coverage of residential units, the visible greening of surrounding street space and the public green land around, respectively. Results show that (1) the greening level of residential units in Shenzhen City is generally high, with the three indicators averaging $32.7 \%$, $30.5 \%$ and $15.1 \%$, respectively; (2) the types of residential greening differ per area; and (3) the level of residential greening is affected by development intensity, location, elevation and residential type. Such findings can serve as a reference for improving the greening level of residential units. This study proposes an accessible public green land index as a measure for the spatial relationship between residential units and surrounding green spaces. It suggest that future green space planning should pay more attention to the spatial distribution of public green land, and introduce quantitative indicators to ensure sufficient public green lands around the walking range of residential areas.

Key words: green coverage index; green view index; accessible public green land index; greening characteristics; residential units; residential greening

\section{Introduction}

Urban greening, such as woodlands, shrubs, grasslands and other green spaces, is a widely recognised element of urban landscapes [1,2]. The ecological effects of urban greening include carbon sequestration, air purification, heat island effect alleviation and stormwater runoff filtration and reduction [3,4]. Greening in residential and surrounding areas is an important part of urban greening. Residential urban greening provides opportunities for social integration and physical exercise, which are beneficial to promoting citizens' mental health, relieving stress and 
reducing obesity and violent crimes $[5,6]$.

In comparison with urban parks, street greening and neighbourhood trees play more important roles in the lives of residents. They form green corridors in residential areas and streets, thereby providing multi-dimensional - but sometimes unnoticedbenefits [7-9]. For instance, greening can reduce mental and physical stress, increase perceived safety of urban streets[9]; street trees are associated with lowering asthma risk in children; green walking environments can prolong the life of the elderly; green spaces can alleviate mental fatigue and aggression and the presence of trees can affect people's behaviour, such as encouraging children to walk to school and people to walk and cycle[8]. Research shows that about $90 \%$ of the information received by people in the environment comes from vision. The most commonly seen green landscape amongst residents is 3-D greening, as represented by street greening and neighbourhood trees [10]. The visual evaluation of 3-D greening enables an intuitive understanding of the greening level in residential areas [11].

Extant green space evaluation and research mainly focus on 2-D urban greening [12] but rarely on street greening and neighbourhood trees in residential areas [8]. For many years, China's planning management system evaluated urban greening on the basis of green rate, green coverage index and park land per capita [13]. These indicators can evaluate intuitively and quantitatively the total amount of urban green space [14]. However, they cannot evaluate, guide and control the distribution of greening in residential areas, and the relationship between green space and residential areas, especially the shortage of residential green space services amongst disadvantaged groups. These indicators can evaluate the 2-D greening effect but not the 3-D green resource distribution and landscape effect.

The concept of 'green view index' complements existing standards in the greening and visibility of street greening and neighbourhood trees in residential areas[15]. Recognised by the international community, green view index indicates the proportion of visible greens. Studies have shown that a green view index larger than $30 \%$ brings mental and psychological comfort to people, thereby inducing good physiological and psychological effects[15]. In comparison with parks and green spaces that serve as fixed greening centres, street trees, neighbourhood trees and 3-D greening outside buildings are more flexible. They are the most visible green spaces amongst urban residents because they form green corridors along streets and pedestrian passages[16]. As an essential component of urban green space, street greening has substantially contributed to the attractiveness and walkability of streets [7]. The visibility of greening in residential areas helps increase the public's satisfaction with their living environment and considerably promote public health [17]. Few studies have systematically analysed the distribution of urban residential areas and associated green spaces, including trees, lawns, neighbourhood trees and other green spaces along the streets [18].

The traditional green view index data entail time-consuming and laborious acquisition and analysis[19]. Previous research on the green view index mainly used 
mechanical sampling and camera shooting to obtain photographs and then used Photoshop or other methods to estimate the green view index [20]. Data acquisition and processing consume much effort and resources, yet the amount of data is limited and the system error is large. Existing studies on the green view index generally have small sample sizes because they focus on few cities or parts of a city. Only a few works have systematically explored the spatial distribution differences and influencing factors of the green view index and its relationship with other indicators [18]. In recent years, the availability of data and the progress of computer image processing technology enabled in-depth research on the green view index. Additional channels to acquire urban spatial landscape images were created. Google, Tencent, Baidu and other street view map applications have been used for quantitative studies on the green view index. Street view photos can be obtained directly, efficiently and easily from the internet, which guarantees large sample sizes [21]. Moreover, advancements in image processing technology lead researchers to come up with image processing algorithms and use MATLAB for quick batch computing of the green view index [22]; MATLAB can reduce errors caused by the manual identification of green blocks, thereby improving efficiency.

This study tries to emerge multiple indicators to measure urban residential greening of China. Currently, urban residential types in China are classified into commercial housing, collective dormitories, affordable housing and urban villages of different densities. The supply of green space is also diversified: public green lands and street green spaces provided by the government, green spaces inside residential units provided by the developer, private gardens provided by individuals and balcony greening. Hence, the present study aims to answer the following question: Is there a spatial difference in the level of green resources in urban residential spaces? If yes, what are the influencing factors? How can we improve the greening level of urban residential space in the future? This study employs a large sample of street view images and other data to build a green database integrated by multi-source geographic data combined with existing urban greening indicators. It also explores methods for measuring greening level, spatial distribution and regional differences amongst urban residential units.

\section{Data and methods}

\subsection{Case selection}

This study selected Shenzhen, one of the garden cities in China, as its research subject. Located in southern China, Shenzhen is one of the most developed cities in the country and is China's first special economic zone (SEZ). It is adjacent to Hong Kong and has a total area of $1,952 \mathrm{~km}^{2}$ and a total population of 12.53 million at the end of 2017. Hence, it is the largest metropolis with the highest population density in 
China. As of 2017, its forest area reached $793.39 \mathrm{~km}^{2}$ with a forest coverage rate of $40.04 \%$; the green areas from gardens in the city's built-up areas covered $362.67 \mathrm{~km}^{2}$, with a $39.2 \%$ green rate of the built-up area; the park land per capita was $16.04 \mathrm{~m}^{2}$; and the green coverage index of the built-up area was $45.08 \%$ [23].

Shenzhen City is an important model of China's rapid urbanisation in the last 40 years. It has made considerable achievements in urban construction and ecological environment protection. It also leads the country in terms of park construction and greening of residential areas, as well as serves as a model role in the urbanisation of developing countries and regions. As a young city, Shenzhen is also less constrained by the lack of green space apparent amongst old cities. Therefore, it is selected to explore the difference in green resource supply of urban residential space.

\subsection{Residential unit and type identification}

This study used residential units as an analytical sample. A database on the current land use from the Shenzhen Land Planning Department contains 123,325 basic land units and indicates the nature of land use of each land parcel in 2014. This study used the residential parcels in the database as a sample unit. ArcGIS 10.2 spatial analysis tools were used to calculate the area of residential buildings on each parcel based on the Second Buildings Census of Shenzhen City (2014) and the land use in 2014. Approximately $97.1 \%$ of residential buildings were located on four land-use types: urban residential, rural residential, industrial and military lands. The major property types on these land-use types are commercial housing (including affordable housing), informal housing (including urban villages and limited property rights houses), factory dormitories (including several limited property rights houses) and military property houses, respectively. Altogether, these property types involve 19,575 land-use units. The remaining $2.9 \%$ of residential buildings are scattered on 36 land-use types, which involve 5,359 land-use units. As such, the study focused on four major residential types and used the land parcels of the four types of land use as basic residential units. It also calculated the base and building areas of each building in each parcel. According to its land use and building type, 'apartment' was not identified as 'commercial housing'. The number of apartments in Shenzhen is small and their land-use types are very diverse. Commercial housing was divided into high-density (floor area ratio $\geq 2$ ) and low-density (floor area ratio $<2$ ) commercial housing to further distinguish the greening characteristics of commercial houses at different densities.

Table 1 Statistics of different residential units

\begin{tabular}{ccc}
\hline Type of residential unit & $\begin{array}{c}\text { Number of residential } \\
\text { units }\end{array}$ & $\begin{array}{c}\text { Gross residential area } \\
\left(\mathbf{m}^{\mathbf{2}} \mathbf{)}\right.\end{array}$ \\
\hline $\begin{array}{c}\text { Informal housing } \\
\text { High-density commercial } \\
\text { housing }\end{array}$ & 3,737 & $192,216,070$ \\
Low-density commercial & 4,582 & $248,956,472$ \\
& 1,202 & $36,327,790$ \\
\hline
\end{tabular}




\subsection{Calculation of three greening indicators}

The study integrated existing methods to measure urban greening. It proposed three greening indicators, namely, green coverage index (hereinafter referred to as GCI), green view index (hereinafter referred to as GVI) and accessible public green land index (hereinafter referred to as GLI), to measure the green coverage of residential units, the visible greening of surrounding street space and the public green land around the walking range, respectively.

GVI was calculated using street view photos. These images were collected from Tencent Street View via web crawler and location query (https://map.qq.com/). The capture angle was uniformly set to $0^{\circ}$ (i.e. head up). The same street was sampled at $50 \mathrm{~m}$ intervals when capturing images. Wide streets were sampled along both sides. The main and auxiliary roads were sampled separately, and intersections were regarded as the start and end points of sampling. Images of the front, back, left and right directions were obtained for each sampling point. Each picture contained information such as the unique identifier of the point, latitude and longitude and orientation. We captured street view data of all streets in Shenzhen at June 2017. A total of 292,000 sample points were obtained with 1.168 million street view photos.

The automatic calculation of GVI has two steps: analysis of the colour composition of the street view images and aggregation of point-based GVI. The analysis of colour composition of the street view image was completed by the algorithm function in MATLAB. The colour model of each photo was converted from RGB to HSV. The values of the respective channels were extracted from the digital image. For each pixel, the degree $\left(0^{\circ}-360^{\circ}\right)$ of its colour in the HSV spectrum was calculated; $60^{\circ}-180^{\circ}$ was defined as green. The GVI of each street view image was acquired through the ratio of the number of green pixels to the total number of pixels. The GVI of a point is the average GVI of four street view images at the point. The GVI of the residential unit is the average value GVI of all the sampling points inside the unit and the surrounding street space (a $100 \mathrm{~m}$ buffer zone outside the land boundary). 


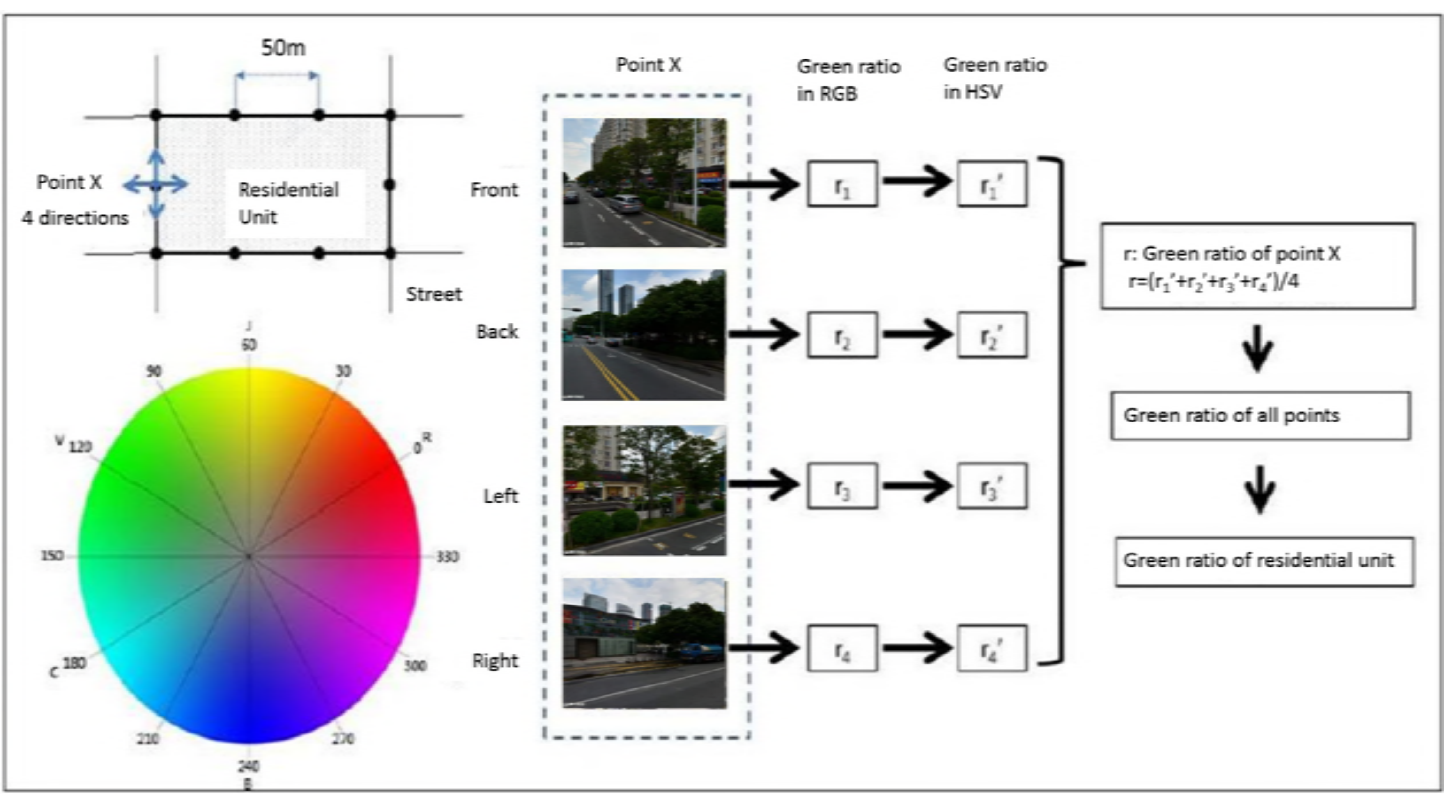

Figure 1 Calculation framework of the GVI

Image source: a redrawing of fig. 3 of [21]

The GCI was calculated based on high-resolution satellite remote sensing image data. The remote sensing processing software was used to fuse the panchromatic and multi-spectral bands of satellite data. The spectral characteristics of multi-spectral bands were employed to extract urban green coverage information. The vector data of urban greening coverage were obtained after field verification and manual correction. This study used a multi-spectral, full-colour SPOT-5 image obtained on November 30, 2013. PCI Geomatica was used for fusion and ENVI was used for image processing to obtain images covering the whole city of Shenzhen. The object-oriented method was used for image segmentation, whilst the support vector machine was used for supervised classification to obtain the green coverage map of Shenzhen [24]. The GCI of the residential unit is the proportion of the green coverage area within the land area of the residential unit.

In terms of GLI, this study integrated accessibility and green rate to quantitatively compare the service level of public green land around different residential units [25]. We proposed an indicator of public green land index of a residential unit within walking distance (GLI). The calculation of GLI was based on current land-use data. The proportion of public green land within a certain distance around the residential unit was measured. According to the European Environmental Agency, people should be able to reach an urban green space within 15 minutes of walking, which is equivalent to $900-1000 \mathrm{~m}$. The minimum green supply target set by the Netherlands is $60 \mathrm{~m}^{2}$ per household within $500 \mathrm{~m}$ of the residential area, while the British standard suggests a minimum area of 2 ha within $300 \mathrm{~m}$ [25]. China's 'National Evaluation Standards of Garden Cities' proposed that 'the layout of urban public green land should be reasonable with a service radius of 500 m'. By contrast, 'Shenzhen City Planning Standards and Guidelines' proposed that the service radius of community parks should be $300-500 \mathrm{~m}$. In the present study, $500 \mathrm{~m}$ buffer zone of the residential unit was used. The GLI was calculated as follows. On the basis of the citywide 
land-use vector data, the ratio of various public green lands (including urban, community and country parks, open space, mountainous parks), within the residential unit and $500 \mathrm{~m}$ buffer zone of the residential unit, to the total area was calculated.

\subsection{Database establishment and statistical analysis}

We established a comprehensive database of multi-dimensional greening of the 19,575 residential units identified by the above method, using the ArcGIS 10.2 spatial analysis tool. Statistical analysis showed that the area of some residential units was too small, and the number of green-view samples around some residential units was small or even zero. To minimise statistic error, residential units with less than 10 green-view sample points, or small parcels with areas less than $2000 \mathrm{~m}^{2}$, or with total residential floor areas less than $1000 \mathrm{~m}^{2}$ were excluded. The final number of residential units that were included in the statistical analysis was 14,196 . The study measured three greening indicators of each residential unit: GCI, GVI and GLI. It analysed the spatial distribution characteristics, regional differences and influencing factors of greening of residential units.

\section{Results}

\subsection{Overall greening level and correlation amongst different}

\section{indicators}

The GCI of residential areas in Shenzhen City is relatively high, with an average GCI inside residential units of $32.7 \%$. This value is lower than the GCI of the built-up area published in the relevant statistics (45.08\%) [23]. The latter includes a large number of urban green land and forestry lands. The average value of GLI was $15.1 \%$, which was slightly lower than the public green land rate (19.0\%) of the city's built-up area. The average GVI was $30.5 \%$, which was slightly higher than the $30 \%$ standard recommended by relevant literature [15].

Amongst the three greening indicators, GCI had the maximal average value, whereas GLI had the minimal average value. GLI and GCI had large standard deviations, whereas GVI had the smallest. As such, the amount of greening and public green land within different residential units differed greatly. However, little difference was observed in the visible greening landscape around the residential units.

The high GCI inside residential units is related to the strict real estate development policy on green land in residential areas in China. The 'Code of Urban Residential Areas Planning \& Design' stipulates that the green land rate should not be lower than $30 \%$ in new urban areas and not lower than $25 \%$ in rebuilt old areas. 
Commercial houses in Shenzhen are mostly located in new residential areas with a high green land rate. The GCI is even higher than the green rate because the land areas of tree projection, roof garden and grass-planting bricks are included in its calculation.

The GLI is $15.1 \%$ in average, and the average public green area in the $500 \mathrm{~m}$ buffer zone of residential units is 11.9 ha, which is higher than the 4.4 ha of a recent Western study [25]. The large number of mountain parks results in a relatively high public green land rate in Shenzhen. The 'Code for Classification of Urban Land Use and Planning Standards of Development Land (China)' proposes that the ratio of green space and urban square should be $10.0 \%-15.0 \%$. In addition, the surface area of mountains in Shenzhen City accounts for $62 \%$ of its total land area. Given that many residential units are built besides hills or mountains, residents can reach mountain or country parks within $500 \mathrm{~m}$. However, a high standard deviation reflects a large spatial difference in the distribution of public green land.

The average GVI of residential units in Shenzhen is $30.5 \%$, which indicates a high level of street greening level around residential units. However, the standard deviation of GVI is small, which reflects small difference in street greening around different residential units. Shenzhen's greening management regulations dictate that street greening is directly invested, constructed and managed by the government. The municipal and district governments are responsible for the main and auxiliary roads. Therefore, the spatial difference of the greening level around residential units is very small.

Table 2 Basic attributes of residential units

\begin{tabular}{lrrrr}
\hline \multicolumn{1}{c}{ Variables } & \multicolumn{1}{c}{$\begin{array}{c}\text { Mean } \\
\text { value }\end{array}$} & $\begin{array}{c}\text { Standard } \\
\text { deviation }\end{array}$ & \multicolumn{1}{c}{$\begin{array}{c}\text { Maximum } \\
\text { value }\end{array}$} & \multicolumn{1}{c}{$\begin{array}{c}\text { Minimum } \\
\text { value }\end{array}$} \\
\hline Parcel area $\left(\mathrm{m}^{2}\right)$ & $24,786.75$ & $34,286.35$ & $787,620.81$ & $2,000.01$ \\
Number of buildings in & 35 & 84 & 3142 & 1 \\
each unit & & & & \\
Gross floor area $\left(\mathrm{m}^{2}\right)$ & $52,038.56$ & $70,226.51$ & $1,106,262.79$ & $1,216.80$ \\
Gross residential area $\left(\mathrm{m}^{2}\right)$ & $36,714.03$ & $60,994.06$ & $990,345.75$ & $1,000.99$ \\
Building density & 0.473 & 0.165 & 1.000 & 0.001 \\
Floor area ratio & 2.66 & 2.28 & 27.79 & 0.01 \\
GLI & 0.151 & 0.149 & 0.982 & 0.000 \\
GVI & 0.305 & 0.084 & 0.726 & 0.050 \\
GCI & 0.327 & 0.137 & 0.922 & 0.000 \\
\hline
\end{tabular}

A significant positive correlation was observed amongst the three indicators. The correlation coefficient between GVI and GCI was 0.241 (sig. $<0.001$ ); the correlation coefficient between GVI and GLI was 0.187 (sig. $<0.001$ ); and the correlation coefficient between GCI and GLI was 0.022 (sig. $<0.01$ ). The measurements of the greening level of the three indicators overlapped to some extent. They measure the greening inside a residential unit, the visible greening of surrounding street space and the public green land within walking distance, respectively. Therefore, the greening 
measured by GVI and that by the other two indicators much overlapped, which explains its strong correlation. The measurement for GCI and GLI overlapped much less. Thus, their correlation is weak.

\subsection{Spatial Differences of residential greening}

The residential greening varies in different areas. On a citywide scale, the residential greening level in the east is higher than that in the west. The east area has more mountains and forests than the west, whereas the west has more plains and fewer forests. Moreover, residential greening in the south is better than that in the north because the former is more developed. In terms of differences between districts inside and outside the original SEZ, both GVI and GCI of residential units in the original four SEZ districts (Luohu, Futian, Nanshan and Yantian) are higher than those in the six districts outside the original SEZ (Figure 3).
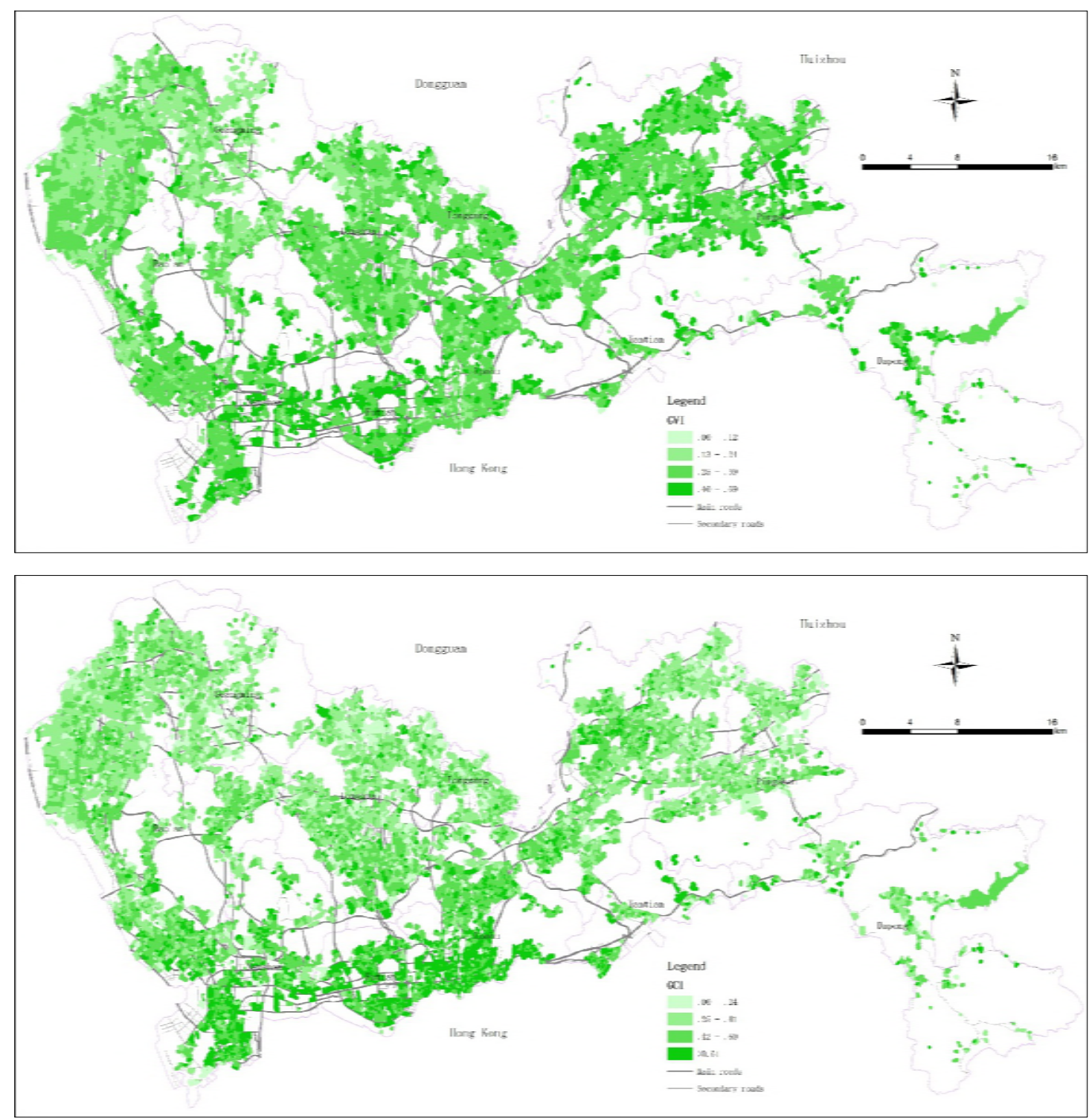


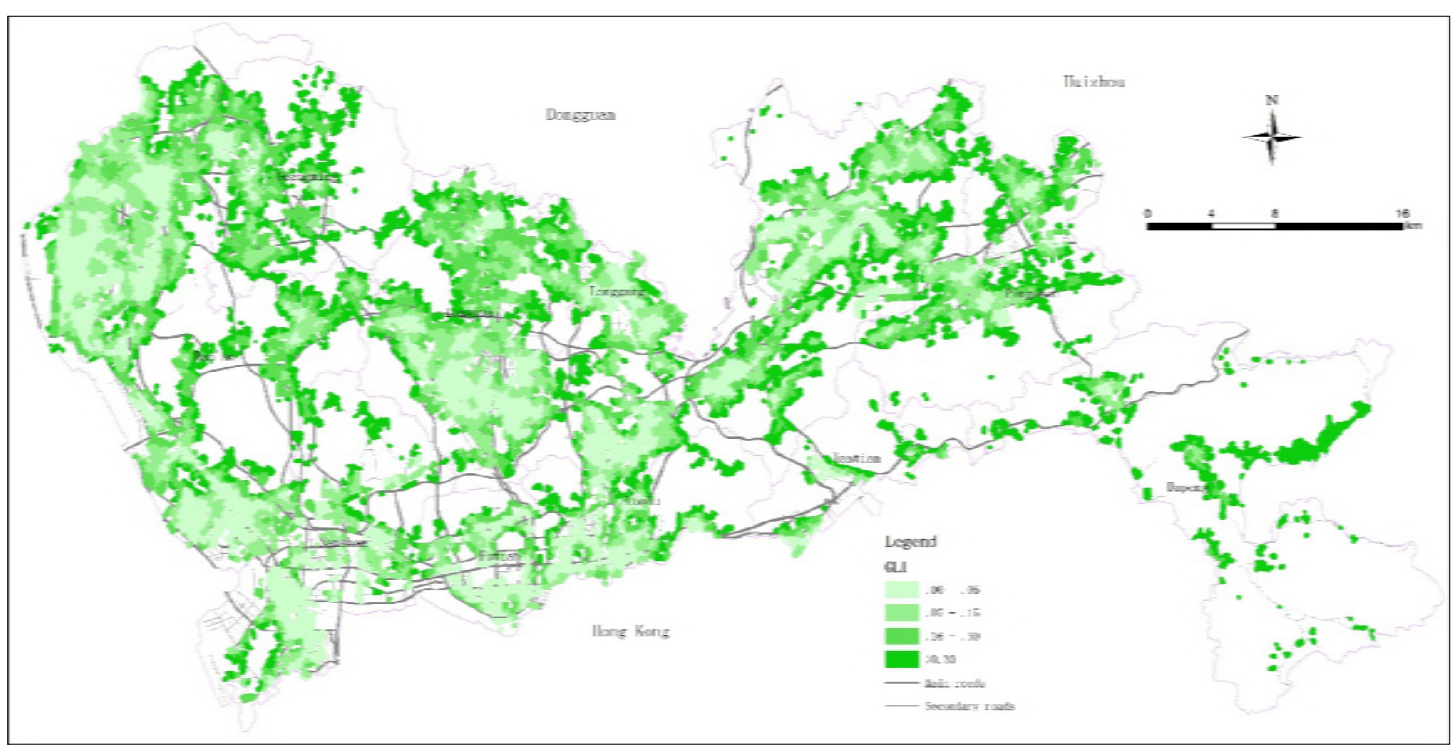

GVI (top) / GCI (middle) / GLI (bottom)

Figure 2 Distribution of three greening index values of residential units

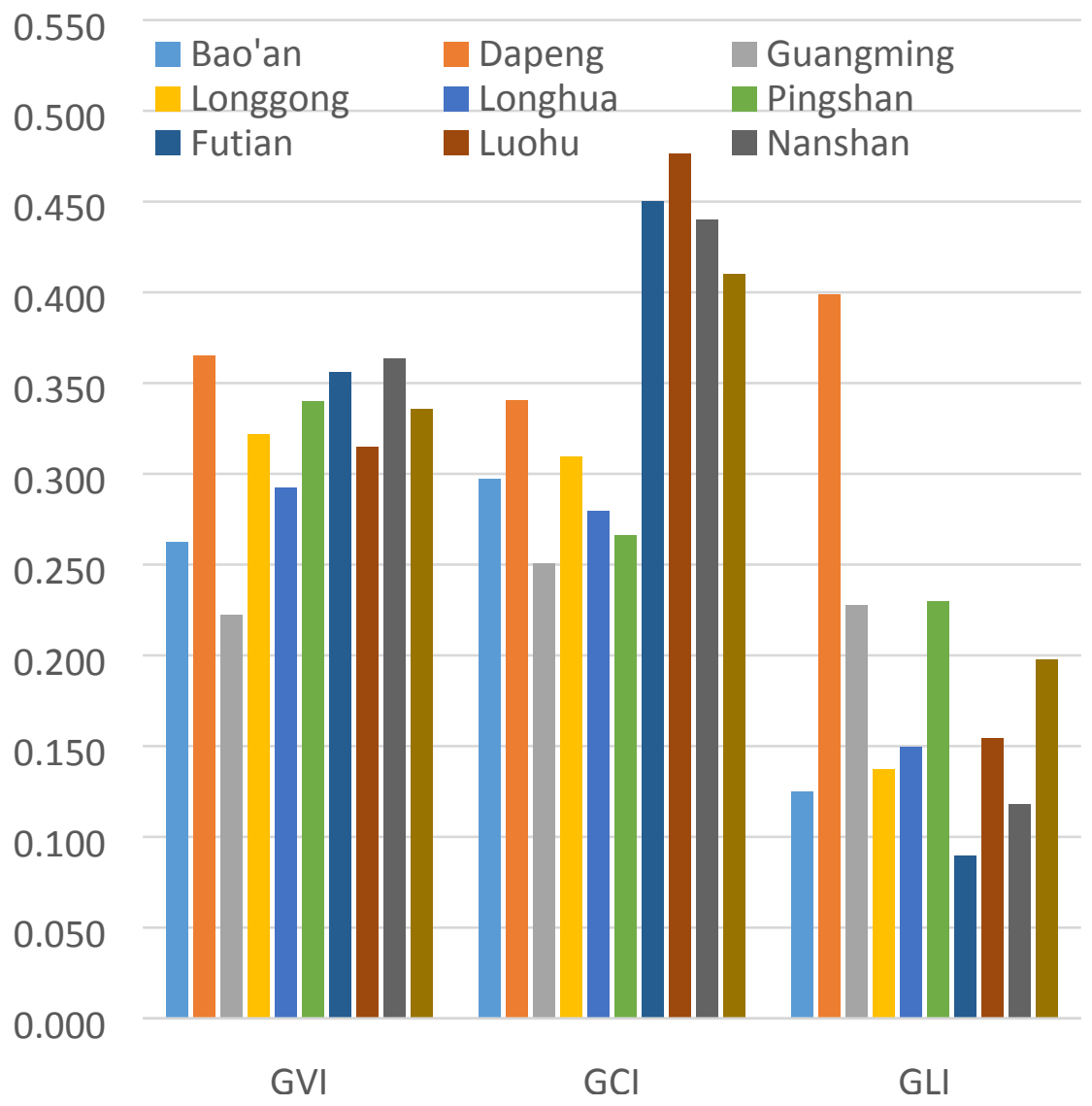

Figure 3 Mean values of three greening indicators in different regions

In terms of GCI, the housing market in the original four SEZ districts is relatively mature, thus their overall GCI are also relatively high, especially for commercial housing of all kinds, which has a $41 \%-47 \%$ GCI. The GCI of all other districts outside the original SEZ is relatively low because their development started relatively late. Currently, these areas have many informal housing and industrial dormitories. 
Moreover, their building density is high, leaving few spaces for greening in residential areas. Hence, their average GCI is relatively low, between $25 \%$ and $34 \%$.

Generally, each district differs slightly in terms of GVI. The average value of each district falls between $22 \%$ and $37 \%$. Amongst the districts inside and outside the original SEZ, Dapeng and Pingshan district have relatively high greening levels. Dapeng district has the highest average GVI of 36.5\%, followed by Nanshan District and Futian District at 36\%. Guangming, Baoan and Longhua districts outside the original SEZ have low average GVI value.

The average GLI of residential units in the whole city is $15.1 \%$. Considerable differences were observed amongst districts whose average value falls between $9 \%$ and $40 \%$. Dapeng District still has the highest value, with a GLI of 39.9\%, followed by Pingshan, Guangming and Yantian with GLI of above 20\%. These areas have many forests and country parks, and many residential areas are built on mountainside. Futian, Nanshan and Baoan districts have the lowest GLI. Generally, the number and area of the mountain parks in these areas are small. Their public green lands are mainly comprehensive parks and small mountain parks. Hence, they have low GLI value.

\subsection{Greening differences amongst different types of}

\section{residential units}

Different types of residential units present large greening differences. Low-density commercial and military housings have the highest greening levels, with high GVI, GCI and GLI value. By contrast, informal housing and factory dormitories have the lowest greening levels, with lower GVI and GCI value. Military housing comprises real estate developments that rely on military facility land. Most houses in such developments are located in good environments and have high greening levels. High-density commercial housing has the lowest GLI. However, low-density commercial housing has the highest GLI because many of them (including villas) are geographically located in well-greened areas, such as places around country parks and mountain basins. Commercial houses built in the early stage of urban development are mostly low density. Most of them are located in places with good natural environment, around a comprehensive park, for example.

Informal housing and factory dormitories have the lowest greening levels. Their GVI are low because most of these residential spaces are located on collective village land, where streets are generally narrow, with less or no greening. Their GCI are also very low. The building densities of these residential spaces are generally very high. As most of these spaces are built spontaneously by villagers or workers, they lack unified planning management, which leaves limited space for greening. These residential spaces also have fewer public green lands within walking distance, reflecting the overall low greening investment by the village collective. 


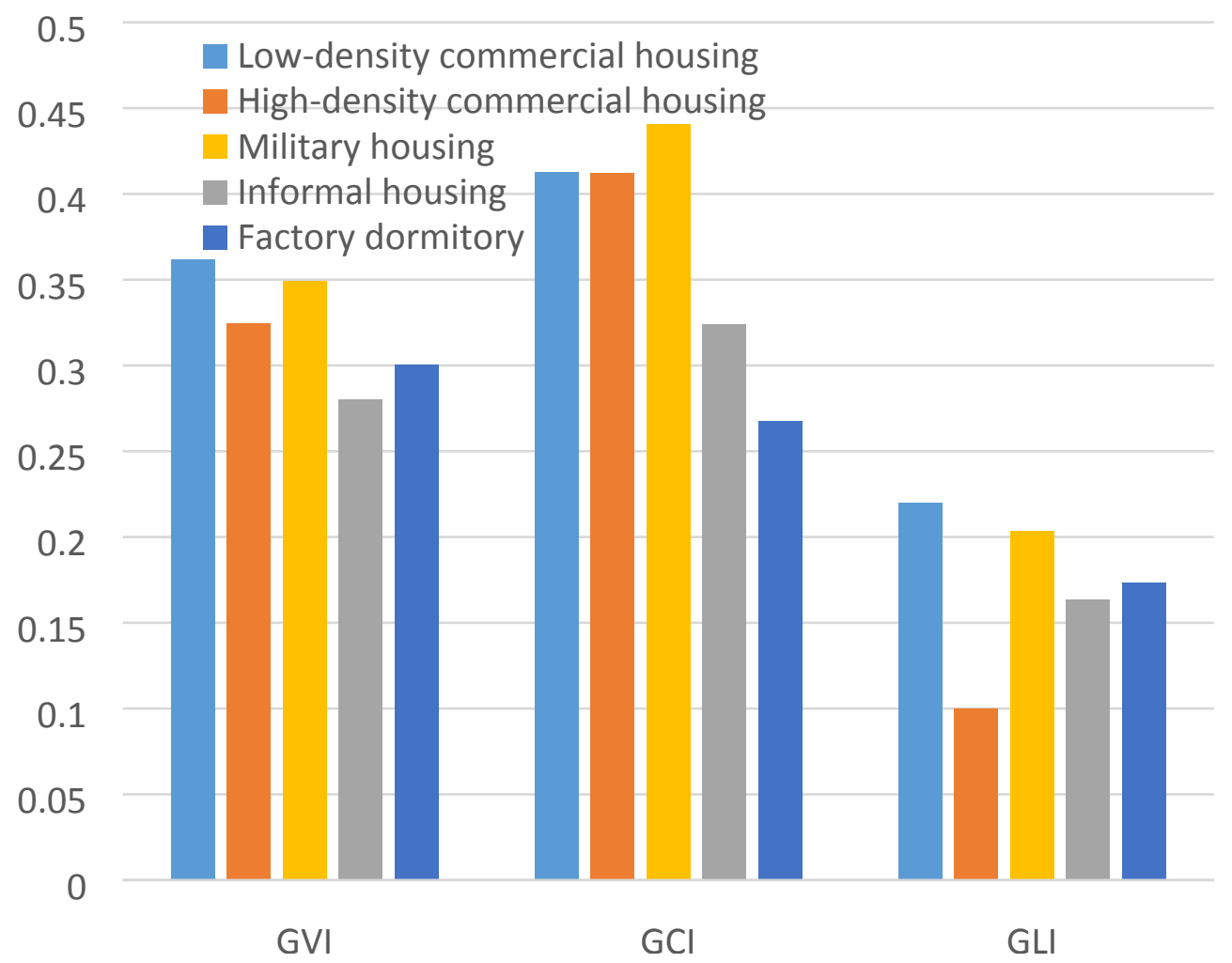

Figure 4 Mean values of three greening indicators for different residential types

\subsection{Factors affecting residential greening}

To explore the factors affecting the greening of residential units, we selected 12 variables and established linear regression models in an attempt to identify the geospatial factors related to the residential greening level. The variables include the characteristics of the residential unit itself (i.e. parcel area, number of buildings, building density, floor area ratio, whether it is a commercial house or a factory dormitory), location of the residential unit (i.e. whether it is in the original SEZ, distance from the $\mathrm{CBD}$, the number of bus lines around) and the surrounding environment of the residential unit (i.e. whether it is backed by a mountain, whether it is facing water, elevation). When selecting the variables, we consulted related research [3,21] and considered the availability of data and common knowledge.

Three linear regression models were established using the Enter method in SPSS 22.0. The dependent variables are GVI, GCI and GLI, respectively. The VIF values of all variables in the models are less than 3 . Hence, no significant collinearity exists amongst the variables. The corrected regression coefficients for each variable are $0.195,0.319$ and 0.265 , respectively. Thus, the model can be used to interpret greening level, especially GCI model.

Amongst the three models, the symbols (positive and negative correlations) of most variables are consistent. Therefore, these variables have a consistent influence 
on the three greening indicators. The regression coefficients of building density, floor area ratio and distance from CBD are negative (and sig. $<0.001$ ), whereas those of elevation-whether it is inside the original SEZ and whether it is commercial housing - are positive (and sig. $<0.001$ ). Thus, residential units with high greening levels have the following characteristics: low development intensity (low building density and small floor area ratio), close to CBD, high elevation, located in the original SEZ or belong to commercial housing. Amongst the other factors, the number of buildings (negative correlation) and whether it is a factory dormitory (negative correlation) significantly affect the GVI. By contrast, the GCI is significantly affected by whether the residential unit is a factory dormitory (negative correlation) and its parcel area (negative correlation). Specifically, the larger the number of buildings inside a residential unit, the lower the GVI; and the larger the parcel area, the lower the GCI.

Table 3 Standardised coefficients and significance level of the regression model

\begin{tabular}{|c|c|c|c|c|}
\hline Variable types & Variables & GVI & GCI & GLI \\
\hline Characteristics & Parcel area & .018 & $-.053 * *$ & -.019 \\
\hline of residential & Number of buildings & $-.073 * *$ & $-.030 *$ & -.016 \\
\hline \multirow[t]{4}{*}{ units } & Building density & $-.179 * *$ & $-.151 * *$ & $-.106^{* *}$ \\
\hline & Floor area ratio & $-.043 * *$ & $-.071 * *$ & $-.051 * *$ \\
\hline & $\begin{array}{l}\text { Whether it is commercial } \\
\text { housing (yes }=1 \text { ) }\end{array}$ & $.172 * *$ & $.101 * *$ & $.050 * *$ \\
\hline & $\begin{array}{l}\text { Whether it is a factory } \\
\text { dormitory (yes }=1 \text { ) }\end{array}$ & $-.088 * *$ & $-.154 * *$ & -.026 \\
\hline \multirow[t]{3}{*}{ Location } & $\begin{array}{l}\text { Whether it is in the } \\
\text { original SEZ (yes }=1 \text { ) }\end{array}$ & $.363 * *$ & $.273 * *$ & $.312 * *$ \\
\hline & Distance from CBD & $-.195 * *$ & $-.067 * *$ & $-.324 * *$ \\
\hline & Number of bus lines & -.016 & .018 & -.038 \\
\hline \multirow[t]{6}{*}{$\begin{array}{l}\text { Surrounding } \\
\text { environment }\end{array}$} & $\begin{array}{l}\text { Whether it is backed by a } \\
\text { mountain (yes }=1)\end{array}$ & .032 & .011 & -.006 \\
\hline & $\begin{array}{l}\text { Whether it is facing water } \\
\text { (yes }=1 \text { ) }\end{array}$ & $-.061 *$ & -.008 & $-.021 *$ \\
\hline & Elevation & $.274 * *$ & $.053 * *$ & $.260 * *$ \\
\hline & Sample quantity & 14196 & 14196 & 14196 \\
\hline & $\operatorname{adj} R^{2}$ & 0.195 & 0.319 & 0.265 \\
\hline & F value & 287.7 & 553.3 & 426.1 \\
\hline
\end{tabular}

\section{Discussions and Conclusions}

This study established a large sample urban residential greening database based 
on multi-source geographic data in Shenzhen City. It integrated existing methods for measuring urban greening and proposed three greening indicators, namely, GCI, GVI, and GLI, to measure the green coverage of residential units, the visible greening of surrounding street space and the proportion of public green land within the walking range, respectively.

Results show that residential greening differs greatly in different areas. The level of residential greening in the east is higher than that in the west. Moreover, the greening level in the districts inside the original SEZ is higher than that in the districts outside the original SEZ. The greening of different types of residential units also varies. The greening level of low-density commercial housing is the highest, whereas that of informal housing and factory dormitories is the lowest. Regression analysis finds that residential units with low development intensity (low building density and small floor area ratio), close to CBD, at high elevation, located in the original SEZ and belong to commercial housing have high greening levels, a finding that is basically consistent with the findings of related research [21]. To improve the level of residential greening, the present study suggests paying attention to the greening of residential units that are far from the $\mathrm{CBD}$, at low elevation and located outside the original SEZ, as well as those that have high development intensity or are informal housing and factory dormitories.

This study shows that the three greening indicators have both commonalities and differences. The average GCI is the largest, whereas the average GLI is the smallest. Therefore, the greening measurements of the three indicators have overlaps, which explain the strong correlations amongst them. The greening level of residential units in Shenzhen City is generally high, with the averages of GCI, GVI, and GLI being $32.7 \%, 30.5 \%$ and $15.1 \%$, respectively. The values of the three indicators, which are calculated based on large sample units, are consistent with the findings of the relevant statistical data and research $[21,23]$. The methods and indicators proposed in this study have practical significance and can be used to supplement existing greening indicators of residential areas.

In addition, this study finds that the difference in spatial distribution of GLI is the largest amongst the several types of greening of residential units, whereas the spatial difference of GVI is the smallest. Accessible public green land (GLI) refers to urban parks, community parks, country parks, mountain parks and other urban public green lands. Relevant planning standards mainly control the total amount of urban public green land but fail to effectively control its spatial distribution, especially its relationship with residential units [26]. Street greening is generally invested, constructed and maintained by government departments at all levels, and thus the spatial difference is small. In terms of green coverage inside the residential unit, due to the stipulation of residential greening in the 'Code of Urban Residential Areas Planning \& Design' that 'green rate should not be lower than $30 \%$ in new urban areas and should not be lower than $25 \%$ in rebuilt old areas', the overall spatial difference is not large. 
Previous studies mostly used administrative districts as units to measure the accessibility of public green land or used public green land per capita as an indicator to measure the supply of public green land per capita [27,28]. However, both indicators failed to measure the spatial relationship between residential units and surrounding green spaces [29]. We integrated accessibility and green land rate for the first time in literature to our best knowledge. We proposed and measured the GLI and found that this indicator could well measure the spatial relationship between residential units and surrounding green spaces. In addition, it found that the spatial difference of GLI is greater than those of the GVI and GCI. Therefore, future green space planning should pay attention to the spatial distribution of public green land. Quantitative indicators should also be introduced to ensure the proportion of public green lands within walking distance of residential areas.

Acknowledgements: We would like to thank CitoryTech for providing us technical support in this study. And we would like to thank the National Natural Science Foundation of China (NSFC), Project Number 51408367 for funding this study.

\section{References}

1. Koohsari, M.J.; Mavoa, S.; Villanueva, K.; Sugiyama, T.; Badland, H.; Kaczynski, A.T.; Owen, N.; Giles-Corti, B. Public open space, physical activity, urban design and public health: Concepts, methods and research agenda. Health Place 2015, 33, 75-82.

2. Ward Thompson, C.; Roe, J.; Aspinall, P.; Mitchell, R.; Clow, A.; Miller, D. More green space is linked to less stress in deprived communities: Evidence from salivary cortisol patterns. Landscape and Urban Planning 2012, 105, 221-229.

3. Chen, Y.; Liu, X.; Gao, W.; Wang, R.Y.; Li, Y.; Tu, W. Emerging social media data on measuring urban park use. Urban Forestry \& Urban Greening 2018, 31, 130-141.

4. Larson, L.R.; Keith, S.J.; Fernandez, M.; Hallo, J.C.; Shafer, C.S.; Jennings, V. Ecosystem services and urban greenways: What's the public's perspective? Ecosystem Services 2016, 22, 111-116.

5. Bertram, C.; Rehdanz, K. The role of urban green space for human well-being. Ecological Economics 2015, 120, 139-152.

6. Goličnik Marušić, B. Discrepancy between likely and actual occupancies of urban outdoor places. Urban Forestry \& Urban Greening 2016, 18, 151-162.

7. Li, X.; Zhang, C.; Li, W.; Kuzovkina, Y.A.; Weiner, D. Who lives in greener neighborhoods? The distribution of street greenery and its association with residents' socioeconomic conditions in Hartford, Connecticut, USA. Urban Forestry \& Urban Greening 2015, 14, 751-759.

8. Pham, T.-T.-H.; Apparicio, P.; Landry, S.; Lewnard, J. Disentangling the effects of urban form and socio-demographic context on street tree cover: A multi-level analysis from Montréal. Landscape and Urban Planning 2017, 157, 422-433.

9. Harvey, C.; Aultman-Hall, L.; Hurley, S.E.; Troy, A. Effects of skeletal streetscape design on perceived safety. Landscape and Urban Planning 2015, 142, 18-28.

10. Lin, Y.H.; Tsai, C.C.; Sullivan, W.C.; Chang, P.J.; Chang, C.Y. Does awareness effect the restorative function and perception of street trees? Front Psychol 2014, 5, 906.

11. Xi, X.; Min, L. Green Patch Density: Study on the Index for Planning and Layout of Green 
Space in High-density Cities. Chinese Landscape Architecture 2017, 92-102.

12. Ying-shu, Y.; Jin-hui, P.; De-qiong, S.; Hong-can, Z.; Yan-ning, H. Advance in Evaluation Index System of Green Land Plan of Urban Road. JOURNAL OF NORTHWEST FORESTRY UNIVERSITY 2007, 193-197.

13. Xiang, Z.; Zhang, X.; Longbin, H.E.; Hui, Z. Equity Assessment on Urban Green Space Pattern Based on Human Behavior Scale and Its Optimization Strategy:A Case Study in Shenzhen. Acta Scientiarum Naturalium Universitatis Pekinensis 2013, 49, 892-898.

14. Yunfeng, H.U.; Zhao, G.; Zhang, Y. Analysis of Spatial and Temporal Dynamics of Green Coverage and Vegetation Greenness in Beijing. Journal of Geo-Information Science 2018.

15. Aoki, Y. Trends of Researches on Visual Geenery since 1974 in Japan. Environmental Information Science 2006, 34, 46-49.

16. Yu, S.; Yu, B.; Song, W.; Wu, B.; Zhou, J.; Huang, Y.; Wu, J.; Zhao, F.; Mao, W. View-based greenery: A three-dimensional assessment of city buildings' green visibility using Floor Green View Index. Landsc. Urban Plan. 2016, 152, 13-26.

17. Tennessen, C.M.; Cimprich, B. Views to nature: Effects on attention. J.environ.psychol 1995, $15,77-85$.

18. Li, X.; Zhang, C.; Li, W.; Ricard, R.; Meng, Q.; Zhang, W. Assessing street-level urban greenery using Google Street View and a modified green view index. Urban Forestry \& Urban Greening 2015, 14, 675-685.

19. Jiang, B.; Larsen, L.; Deal, B.; Sullivan, W.C. A dose-response curve describing the relationship between tree cover density and landscape preference. Landsc. Urban Plan. 2015, 139, 16-25.

20. Zhao, Q.; Tang, H.; Wei, D.; Qian, W. Spatial visibility of green areas of urban greenway using the green appearance percentage. Journal of Zhejiang A \& F University 2016.

21. Long, Y.; Liu, L. How green are the streets? An analysis for central areas of Chinese cities using Tencent Street View. PLoS One 2017, 12, e0171110.

22. Rai, A. Designing green stormwater infrastructure for hydrologic and human benefits: An image based machine learning approach. University of Illinois, 2013.

23. Bureau, S.U.M. Shenzhen National Land Greening White Paper (2016-2017) . 2018.

24. Tu, W.; Hu, Z.; Li, L.; Cao, J.; Jiang, J.; Li, Q.; Li, Q. Portraying Urban Functional Zones by Coupling Remote Sensing Imagery and Human Sensing Data. Remote Sensing 2018, 10, 141.

25. Wüstemann, H.; Kalisch, D.; Kolbe, J. Access to urban green space and environmental inequalities in Germany. Landscape and Urban Planning 2017, 164, 124-131.

26. Gupta, K.; Roy, A.; Luthra, K.; Maithani, S.; Mahavir. GIS based analysis for assessing the accessibility at hierarchical levels of urban green spaces. Urban Forestry \& Urban Greening 2016, 18, 198-211.

27. Cohen, D.A.; Han, B.; Nagel, C.J.; Harnik, P.; McKenzie, T.L.; Evenson, K.R.; Marsh, T.; Williamson, S.; Vaughan, C.; Katta, S. The First National Study of Neighborhood Parks: Implications for Physical Activity. Am J Prev Med 2016, 51, 419-426.

28. Wu, J.; Wang, M.; Li, W.; Peng, J.; Huang, L. Impact of Urban Green Space on Residential Housing Prices: Case Study in Shenzhen. Journal of Urban Planning \& Development 2014, \#, 05014023.

29. Tamosiunas, A.; Grazuleviciene, R.; Luksiene, D.; Dedele, A.; Reklaitiene, R.; Baceviciene, M.; Vencloviene, J. Accessibility and use of urban green spaces, and cardiovascular health: findings from a Kaunas cohort study. Environmental Health 2014, 13, 1-11. 
bioRxiv preprint doi: https://doi.org/10.1101/434381; this version posted October 3, 2018. The copyright holder for this preprint (which was not certified by peer review) is the author/funder, who has granted bioRxiv a license to display the preprint in perpetuity. It is made available under aCC-BY 4.0 International license. 